The INL is a

U.S. Department of Energy

National Laboratory

operated by

Battelle Energy Alliance

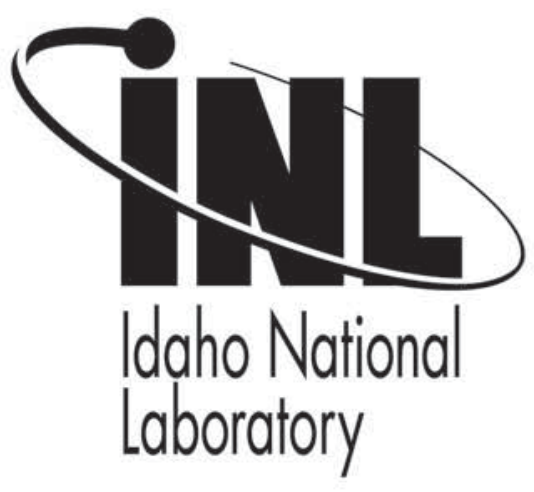

INL/CON-08-14683

PREPRINT

\section{A Preliminary}

\section{Assessment of the}

Occupational Radiation Exposure from

\section{Maintaining the US ITER DCLL TBM}

\section{8th Topical Meeting on Fusion Energy}

\author{
Brad J. Merrill \\ Lee C. Cadwallader \\ Mohamad Dagher
}

\section{September 2008}

This is a preprint of a paper intended for publication in a journal or proceedings. Since changes may be made before publication, this preprint should not be cited or reproduced without permission of the author. This document was prepared as an account of work sponsored by an agency of the United States Government. Neither the United States Government nor any agency thereof, or any of their employees, makes any warranty, expressed or implied, or assumes any legal liability or responsibility for any third party's use, or the results of such use, of any information, apparatus, product or process disclosed in this report, or represents that its use by such third party would not infringe privately owned rights. The views expressed in this paper are not necessarily those of the United States Government or the sponsoring agency. 


\title{
A PRELIMINARY ASSESSMENT OF THE OCCUPATIONAL RADIATION EXPOSURE FROM MAINTAINING THE US ITER DCLL TBM
}

\author{
Brad J. Merrill ${ }^{1}$, Lee C. Cadwallader ${ }^{1}$, Mohamad Dagher ${ }^{2}$ \\ ${ }^{1}$ INL Fusion Safety Program, P.O. Box 1625, Idaho Falls, ID, 83415-3860, Brad.Merrill@inl.gov \\ ${ }^{2}$ University of California Los Angeles, 420 Westwood Plaza, 44-114 Engineering IV, CA, 90095-1597
}

This paper details an Occupational Radiation Exposure (ORE) analysis performed for the US International Thermonuclear Experimental Reactor (ITER) Dual Coolant Lead Lithium (DCLL) Test Blanket Module (TBM). This ORE analysis was performed with the $Q A D M O D$ dose code for maintenance activities anticipated for the US DCLL TBM concept and its ancillary systems. Identification of the maintenance tasks that will have to be performed and estimates of the time required to perform these tasks were developed based on either expert opinion or on industrial maintenance experience for similar technologies. This paper details the modeling activity and the calculated doses for the maintenance activities envisioned for the US DCLL TBM.

\section{INTRODUCTION}

As a Participant Team (PT) member in the International Thermonuclear Experimental Reactor (ITER) Program, the US proposed a Test Blanket Module (TBM) concept called the Dual Coolant Lead Lithium (DCLL) TBM for testing in ITER. ${ }^{1}$ This test module is a scaled version of a concept that the US believes will make an effective blanket module for a fusion demonstration reactor (DEMO). As part of the licensing process for ITER, the ITER International Organization (IO) has requested that TBMs that are to be tested in ITER also obtain an operating license. As part of this licensing process, an analysis of the maintenance activities anticipated for the DCLL TBM and the predicted worker doses associated with those activities must be developed. This analysis is called an Occupational Radiation Exposure (ORE) analysis. This paper summarizes an ORE analysis performed for the US DCLL TBM.

The following section (Section II) describes the physical layout of the PbLi equipment of the DCLL TBM that will be a concern from the standpoint of maintenance and the anticipated maintenance activities for this equipment. Section III presents estimated times for anticipated maintenance activities. Section IV presents the approach taken and source terms used to estimate the worker dose for these activities. Section $\mathrm{V}$ gives the estimated ORE results for maintaining the DCLL TBM. The final section presents conclusions from this ORE analysis.

\section{PHYSICAL LAYOUT OF DCLL TBM}

Fig. 1 contains a schematic of the US DCLL blanket concept. This blanket concept has two separate cooling systems. Fast flowing helium in toroidal channels behind the first wall (FW) and axial channels inside the internal $\mathrm{PbLi}$ flow dividers provide cooling for these $\mathrm{F} 82 \mathrm{H}$ ferritic steel TBM structures. Two PbLi breeding zones are radially situated behind the $\mathrm{FW}$. $\mathrm{PbLi}$ is both the tritium breeding material and coolant for these breeding zones. A SiC-composite inserts in these breeding zones provides thermal insulation for the TBM walls from the poloidally flowing PbLi. In addition, these inserts serve as an electrical insulator to reduce the magnetohydrodynamics (MHD) forces on the flowing PbLi. 


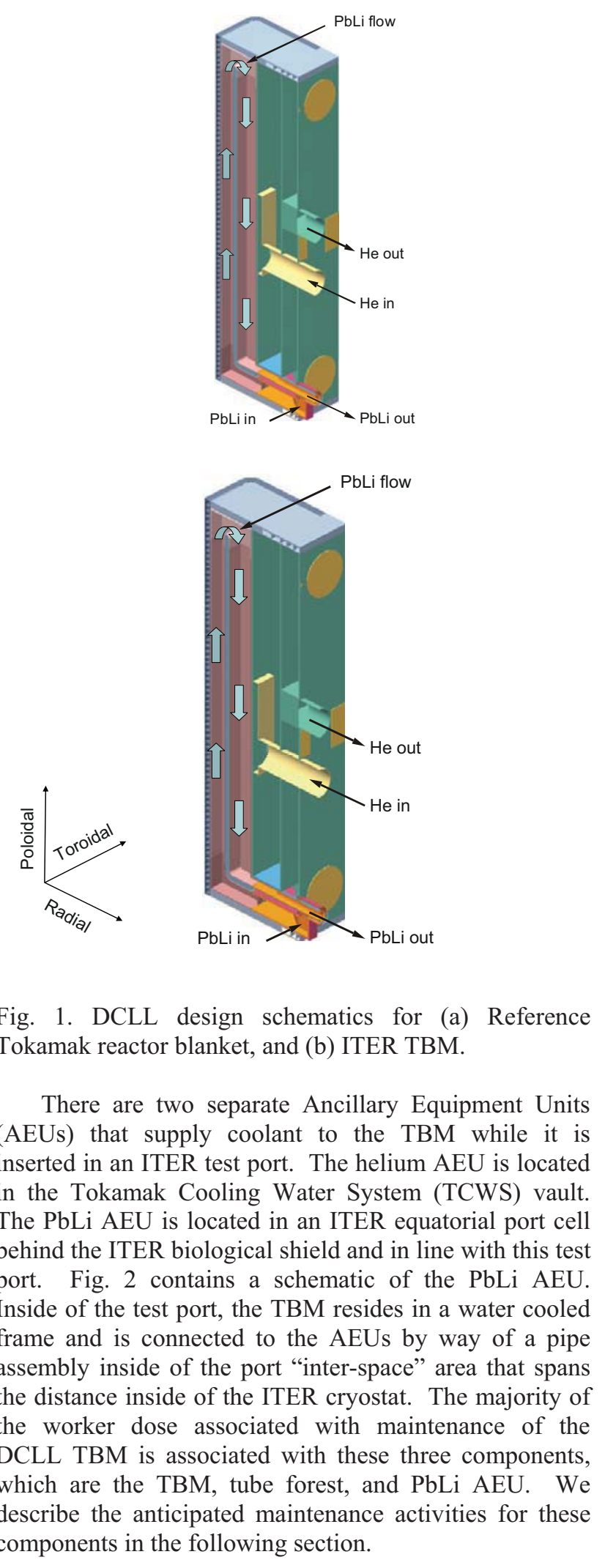

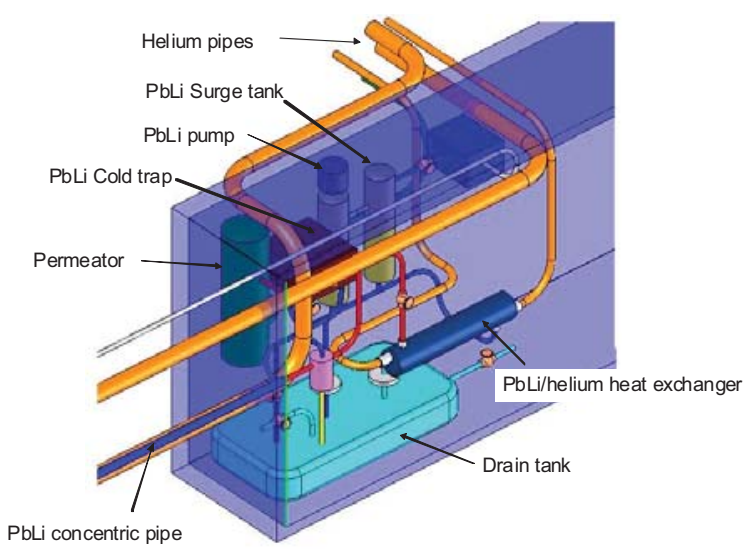

Fig. 2. View of the DCLL PbLi AEU.

\section{ANTICIPATED MAINTENANCE ACTIVITIES}

The major maintenance activity for the DCLL TBM will be the replacement of the TBM, which will occur approximately every other year during ITER DT operation. The maintenance operations for replacing a TBM assembly are: 1) Removal of the AEU from the equatorial port cell area, 2) Clearing the port inter-space area and removing the TBM Frame assembly from the vacuum vessel (VV), 3) Transporting the TBM Frame assembly to the hot cell for further work, 4) TBM Frame assembly re-installation into the equatorial port cell area, and 5) Reconnecting of all piping and provisioning the AEU to support the TBM operation.

Operations in the equatorial port area are assumed to be primarily hands-on operations as long as the $\mathrm{VV}$ test port plug is in place. The TBM frame assembly removal and insertion in the TBM test port is a completely automated process designed by ITER and using ITER's standard port plug removal transporter.

Operations in the port cell area involving the removal of the AEU are considered hands on provided that the proper shielding of the components inside the transporter is installed to limit worker's exposure to radiation. However, the concentric pipe carrying the PbLi flow will have a residual $\mathrm{PbLi}$ film on the inside. Special precautions and additional containment tents will be needed around the pipe during cutting and welding operations to avoid containment contamination of other components. Furthermore, special storage and transportation provisions must be available to handle these components.

Hands on operations are also assumed for the port inter-space area to clear all the piping and provide access for the transporter to remove the TBM assembly. It is 
expected that once the Bio-Shield is opened, workers will be exposed to higher dose rates. An alternative design would be to consider a fully automated remote handling process to remove all piping and fittings from this space.

The Bio-Shield plug removal and design are still under discussion. The current estimate is based on a BioShield plug design made of blocks that could be stacked around the penetrating pipes and could be removed in pieces thus allowing flexible design and simple operation for plug removal and installation. However further design evaluations and discussions with ITER and the other parties sharing the port are needed to agree on a common design that will accommodate the requirements of both TBMs.

Table I contains the summary estimate of times required to perform the TBM replacement. These time estimates are based on expert opinion and on performing multiple concurrent operations at the same time. As more design details become available and more interaction between the parties takes place, the TBM maintenance procedure will most likely develop further and more accurate estimates can be developed.

TABLE I. Time estimates for replacing the DCLL TBM

\begin{tabular}{|l|c|}
\hline \multicolumn{1}{|c|}{ Task Description } & Total Time (p-hr) \\
\hline Remove AEU from port cell area & 65 \\
\hline Bio-shield plug removal & 10 \\
\hline Inter-space pipe removal & 50 \\
\hline Port Flange Preparation & 15 \\
\hline $\begin{array}{l}\text { TBM assembly removal, } \\
\text { transportation to and from hot } \\
\text { cell, and re-insertion }\end{array}$ & 105 \\
\hline $\begin{array}{l}\text { Inter-space pipe assembly and } \\
\text { service equipment Installation }\end{array}$ & 25 \\
\hline Bio-Shield Plug Installation & 120 \\
\hline PbLi AEU installation & 390 \\
\hline \multicolumn{1}{|c|}{ Total } & \\
\hline
\end{tabular}

In addition to the major activity of TBM replacement, components of the $\mathrm{PbLi}$ AEU will have to be maintained during the TBM replacement operation. The anticipated maintenance activities will depend on the failure rate of the components of the PbLi AEU. There is very little data on PbLi systems from which to estimate how often a given component of this AEU will have to be maintained or replaced. As a consequence, data from liquid sodium fission reactors was sought first as representative data for this assessment. Unfortunately, literature searches also revealed that there has been little published information on maintenance of US sodium reactors. Two papers gave some overall radiation exposures for two sodium reactors, the Fast Flux Test Facility (FFTF) near Hanford, Washington, and the Experimental Breeder Reactor-II near Idaho Falls, Idaho. ${ }^{2}$ International sodium-cooled and liquid metal reactor experiences were searched as well. Notably, the Dounreay Fast Reactor, a NaK cooled, 50 MW-thermal plant, and the Phenix sodium-cooled plant. $^{2}$

Some component repair times for water system components in nuclear and in typical industrial environments were also assembled and applied to this $\mathrm{PbLi}$ flow loop. This water system data mainly came from power generation, both fossil and nuclear, and other commercial industries. ${ }^{2}$ Because the $\mathrm{PbLi}$ AEU components are much smaller than the components maintained in these power generation industries, an effort was made to find repair times applicable to small size components. For example, an important source of repair times has been given by Ref. ( 3 ) for shipboard components. These components are much closer to the TBM in size than the large power plant components. When repair times for PbLi AEU components were not available, the repair times for large-scale components were scaled down to apply to the TBM.

The main $\mathrm{PbLi}$ flow loop components, their failure rates and failure probabilities per year, ${ }^{4}$ and the average active repair times for some of the AEU components are listed in Table II. The probabilities of component failure in this table are for the anticipated operational time of the AEU, which is 0.528 full power years (FPYs) over the 15 year life time of the AEU. ${ }^{1}$ Because the TBM will be replaced about every two years, the PbLi AEU will most likely undergo repairs during this same period of time. However, the probabilities of Table 2 are given as annual probabilities to facilitate the ORE analysis.

\section{APPROACH TAKEN AND SOURCE TERMS}

The QADMOD-GP code ${ }^{5}$ was used to perform this ORE analysis. This code is a point kernel gamma-ray

TABLE II. PbLi AEU Component Failure Rate and Repair Time Estimates

\begin{tabular}{|l|c|c|}
\hline Component & $\begin{array}{c}\text { Probability of } \\
\text { failure per year }\end{array}$ & $\begin{array}{c}\text { Repair time } \\
\text { (p-hr) }\end{array}$ \\
\hline $\begin{array}{l}\text { Motor } \\
\text { Controller }\end{array}$ & 0.26 & 5 \\
\hline Pump motor & 0.04 & 100 \\
\hline Pump & 0.28 & 14 \\
\hline Level sensor & 0.016 & 12 \\
\hline Pressure sensor & 0.021 & 12 \\
\hline $\begin{array}{l}\text { Temperature } \\
\text { sensor }\end{array}$ & 0.18 & 12 \\
\hline Check valve & 0.024 & 48 \\
\hline $\begin{array}{l}\text { Motor operated } \\
\text { valve }\end{array}$ & 0.11 & 15 \\
\hline
\end{tabular}




\begin{tabular}{|l|c|c|}
\hline $\begin{array}{l}\text { Flow control } \\
\text { valve }\end{array}$ & 0.022 & 15 \\
\hline Cold trap & 0.039 & 40 \\
\hline Drain tank & 0.004 & 80 \\
\hline Heat exchanger & 0.014 & 60 \\
\hline
\end{tabular}

shielding code, which performs a gamma ray tracing analysis for point-kernel source terms. QADMOD-GP

\section{APPROACH TAKEN AND SOURCE TERMS}

The QADMOD-GP code $^{6}$ was used to perform this ORE analysis. This code is a point kernel gamma-ray shielding code, which performs a gamma ray tracing analysis for point-kernel source terms. QADMOD-GP will allow for either one distributed source, simulated by up to 27,000 point-kernel sources, or up to 1000 user defined pointkernel source locations for a given calculation. Cartesian, cylindrical, or spherical geometries are allowed for defining shielding regions being modeled, with geometric progression buildup factors, attenuation coefficients and material densities available for some shielding materials. The QADMOD-GP shielding code simultaneously calculates the equivalent dose rate $(\mathrm{mSv} / \mathrm{hr})$ for a number of user specified locations.

The primary difficulty in performing an ORE analysis for the DCLL TBM and its PbLi AEU is the very complicated component arrangement of these systems, as can be seen in Figures 1 and 2. Because The QADMODGP code allows up to 1000 point-kernel source definitions per calculation, a dose estimate from all of the AEU components can be performed simultaneously, e.g. without the user summing individual component contributions, within a single calculation, provided that the definition of the point-kernel source strength can be accurately defined to simulate the radiation emitted by these components. This calculation is further complicated by a 1 to $2 \mathrm{~cm}$ thick permanent lead shielding around each component. To accomplish this source definition, the strength of the QADMOD point-kernel source terms representing each component were based adjusted, if required, on to match dose predictions from the MicroShield code. The MicroShield code ${ }^{76}$ is a commercially available code from Grove Software. It is also a deterministic code; that is, MicroShield is a ray tracing code. MicroShield uses simple gamma source geometries, which are spherical, cylindrical, annular, or planar sources. The code allows only one radioactive source per calculation, but this single source can include multiple radionuclides that emit gamma rays. A complete radionuclide database is included with this code to facilitate the user in defining decay rates, gamma ray energies and dose conversion factors. MicroShield will allows the user the possibility to define multiple shields with buildup factors of the same geometries as the source, and as with the source terms, the code includes a database for shield material densities, attenuation coefficients and buildup factors. Figure 3 contains a schematic of our QADMOD-GP model of the PbLi AEU.

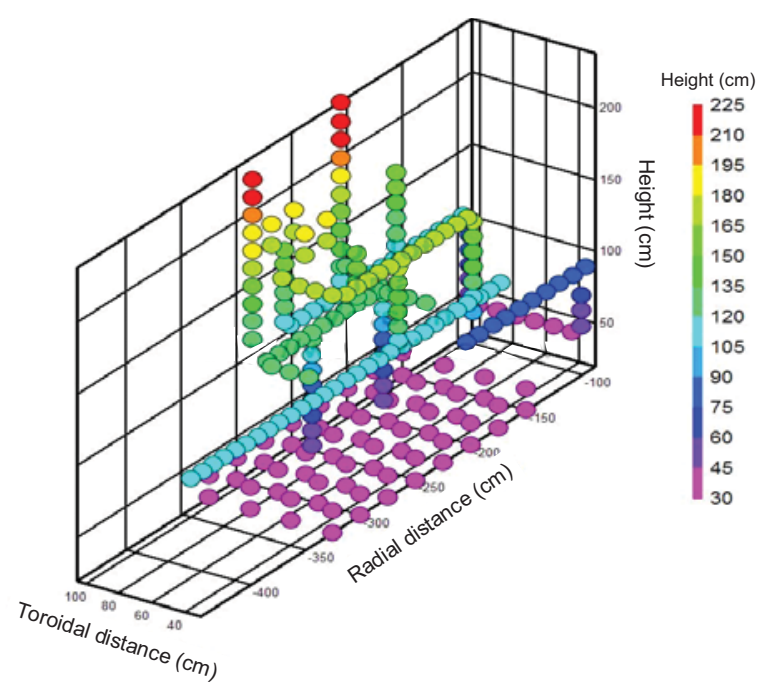

Fig. 3. Schematic of QADMOD-GP model of PbLi AEU.

There will be two sources of radioactive material in the AEU that will produce gamma radiation, activated $\mathrm{PbLi}$ and activated $\mathrm{F} 82 \mathrm{H}$ corrosion products from the internal surfaces of the TBM. During maintenance, most of the PbLi will reside in the drain tank. However, based on TRITEX facility ${ }^{87}$ experience, it was discovered that after draining the TRITEX loop, PbLi films were found on the pipe walls that were on average $\sim 45 \mathrm{mg} / \mathrm{cm}^{2}$. Similar films are expected to adhere to the inner surfaces of the components in the PbLi AEU. According to activation calculations performed for the DCLL TBM, ${ }^{1}$ these $\mathrm{PbLi}$ films will be radioactive, with the activity after one week dominated by $\mathrm{Pb}-203$.

In addition to the activated $\mathrm{PbLi}$ films, the hot surfaces within the TBM and the PbLi outlet pipe wall will undergo corrosion at the $\mathrm{PbLi} /$ Ferritic Steel (FS) interface. The corrosion products from TBM FS surfaces will be activated. These FS corrosion products will mix into the PbLi bulk flow and be deposited, along with the non-radioactive FS corrosion products from the $\mathrm{PbLi}$ outlet pipe, on to the inside surfaces of the lower temperature components of the AEU, such as pipe walls, heat exchanger tubes, valves, permeator tubes, etc. The anticipated corrosion rate of these hot surfaces is 20 $\mu \mathrm{m} / \mathrm{yr}$ at $450^{\circ} \mathrm{C}$ based on experimental data. ${ }^{89}$ This corrosion will only occur at high TBM temperatures and flow rates (e.g. during a pulse), therefore over the lifetime of the AEU (0.528 FPY) this will translate into $\sim 11 \mu \mathrm{m}$ of erosion from the hot surfaces. Because the cool area to hot area ratio in the TBM/AEU system is 6 to 1 , the re- 
deposited corrosion layer thickness in the AEU will will be $\sim 1.8 \mu \mathrm{m}$. According to activation calculations performed for the TBM, ${ }^{1} \mathrm{Fe}-55$ and Mn-54 will dominate the corrosion film activity one week after reactor shutdown.

There is an added complication for the corrosion products, and that is that unlike the $\mathrm{PbLi}$ which is continuously circulating through the neutron radiation field within the reactor, the corrosion products will be deposited outside of this field once they leave the $\mathrm{PbLi}$ flow. Once deposited, they will begin to decay. To account for this decay, the following equation was solved to give the concentration, $\mathrm{C}_{\mathrm{i}} \mathrm{m}^{-3}$, of the $\mathrm{i}^{\text {th }}$ radioactive element within the re-deposition layer:

$$
\mathrm{C}_{\mathrm{i}}=\frac{\mathrm{S}_{\mathrm{i}}}{\lambda_{\mathrm{i}}}\left(1-\mathrm{e}^{-\lambda_{\mathrm{i}} \mathrm{t}}\right)
$$

where $\mathrm{S}_{\mathrm{i}}$ is the source of the $\mathrm{i}^{\text {th }}$ radioactive corrosion product element $\left(\mathrm{m}^{-3} \mathrm{yr}^{-1}\right), \mathrm{t}$ is deposition time $(\mathrm{yr})$, and $\lambda_{\mathrm{i}}$ is the radioactive decay constant of the $i^{\text {th }}$ radioactive specie in the layer $\left(\mathrm{yr}^{-1}\right)$. With the radioactive source terms defined, the radiation field given off by the AEU can now be determined. This radiation field is illustrated in Fig. 4 in terms of dose rate. With this dose rate and the maintenance activity times defined in the previous section, the anticipated annual maintenance dose can now section, the anticipated annual maintenance dose can now be determined as presented in the following section.
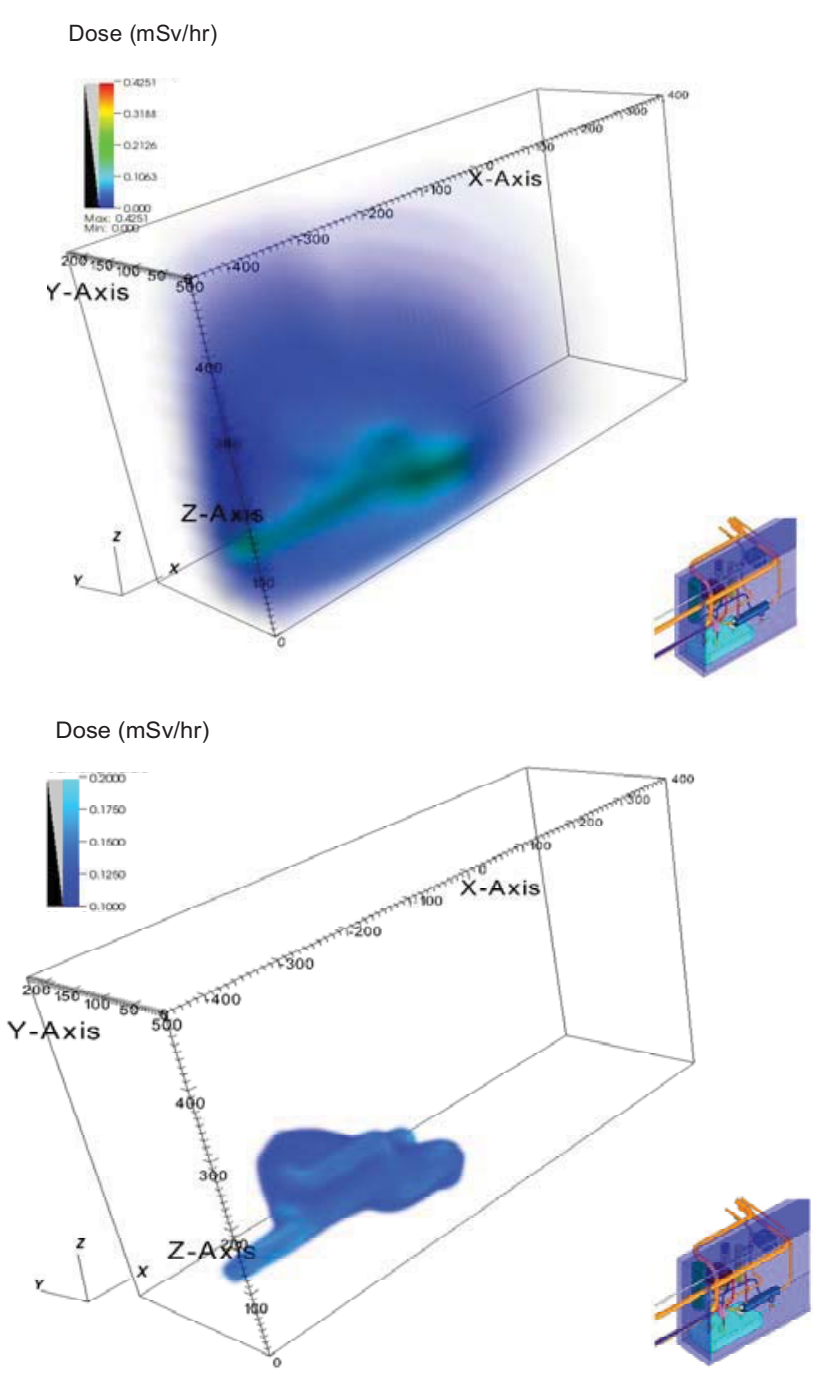

Fig. 4. QADMOD-GP radiation field for the DCLL PbLi AEU.

be determined as presented in the following section.

\section{OCCUPATIONAL RADIATION EXPOSURE ESTIMATE}

An ORE analysis is based on the product of the dose rate incurred by a technician performing a maintenance activity multiplied by the time required to complete the maintenance activity. An exacting analysis would include a time and motion study in the radiation field produced by the DCLL TBM system. This ORE analysis is based on the maximum dose rate at for a given location of maintenance activity, multiplied by the estimated time to complete that maintenance activity. This time estimate also includes the time required by the technicians in preparation to perform a given maintenance activity, but our ORE assumes that the technician is always in the AEU radiation field, making our estimate conservative. 
The dose rates for working around the AEU were obtained from our QADMOD-GP model, but the dose rate for maintenance activities that occur when the AEU and $\mathrm{PbLi}$ inter-space pipe assembly have been removed is that cited in Ref. (109) as $100 \mu \mathrm{Sv} / \mathrm{hr}$. The time estimates also include the time required by the technicians in preparation to perform a maintenance activity, but our ORE assumes that the technician is always in the AEU radiation field, making our estimate conservative.

The total dose estimate for replacing the DCLL TBM is $7.4 \mathrm{p}-\mathrm{mSv}$. This operation will be performed approximately every other year, giving an annual committed dose of 3.7 p-mSv/a.

A similar dose estimate for component repair activities on the AEU, when the AEU is placed in the AEU staging area, gives an annual committed dose for AEU component repair of $\sim 1.5 \mathrm{p}-\mathrm{mSv} / \mathrm{a}$. This brings the combined annual dose commitment to $5.2 \mathrm{p}-\mathrm{mSv} / \mathrm{a}$.

The ITER ORE goal for TBM maintenance is $~ 1 \%$ of the annual maintenance dose for the ITER device. The administrative ORE limit for ITER is $500 \mathrm{p}-\mathrm{mSv} / \mathrm{a},{ }^{9}$ making the goal for DCLL TBM maintenance $\sim 5 \mathrm{p}$ $\mathrm{mSv} / \mathrm{a}$. The predicted value for this dose is $178 \mathrm{p}-\mathrm{mSv} / \mathrm{a},{ }^{9}$ making the goal for DCLL TBM maintenance $\sim 1.8 \mathrm{p}$ $\mathrm{mSv} / \mathrm{a}$. Therefore, some additional effort will be required during the final design phase of the DCLL TBM to reduce the ORE dose for this TBM. As mentioned in Section III, one approach is to remotely remove and reattach the pipe assembly. This would reduce the dose for replacing the TBM by almost one-half, resulting in a combined annual dose of $3.4 \mathrm{p}-\mathrm{mSv} / \mathrm{a}$, which is very close to being $1 \%$ of the. predicted annual dose for all ITER maintenance activities, presently estimated to be $367 \mathrm{p}-\mathrm{mSv} / \mathrm{a}^{9}$

\section{CONCLUSIONS}

In this paper we have analyzed the anticipated worker radiation exposure for maintaining the US ITER DCLL TBM. Exposure estimates were predicted for the most extensive maintenance operation, which is TBM replacement, and the worker doses anticipated for repair of the PbLi AEU of the DCLL TBM when this AEU is parked in the staging area during TBM replacement. Our estimate for the activities examined is a combined annual dose commitment of $5.2 \mathrm{p}-\mathrm{mSv} / \mathrm{a}$, which is slightly above the ITER TBM goal of $1.85 \mathrm{p}-\mathrm{mSv} / \mathrm{a}$. The repair times used here are the best available from the literature, but these times generally apply to larger equipment and are probably overestimating actual times for the TBM equipment. As stated earlierAlso, a time and motion study should be conducted as the design matures to give better estimates of the necessary maintenance times in radiation fields, as opposed to the conservative approach taken here of applying the maximum dose rate for to the entire maintenance operation.

\section{ACKNOWLEDGMENTS}

This work was prepared under the auspices of the US Department of Energy, Office of Fusion Energy Science, under the DOE Idaho Field Office contract number DEAC07-05ID14517.

\section{REFERENCES}

1. C. P. C. WONG, et al., Design Description Document for the U. S. Dual Coolant PbLi (DCLL) Test Blanket Module, General Atomics Report, GAC25027, Rev. 3, November 15 (2005).

2. B. J. MERRILL, L. C. CADWALLADER, AND M. DAGHER, Occupational Radiation Exposure Analysis of US ITER DCLL TBM, Idaho National Laboratory Report, INL/EXT-07-13073, August (2007).

3. D. BUTLER, Guide to Ship Repair Estimates (in Man-Hours), Butterworth Heinemann, Amsterdam, 2000.

4. L. C. CADWALLADER, Preliminary Failure Modes and Effects Analysis of the US Test Blanket Module, INL-EXT-07-13115, Idaho National Laboratory Report August (2007).

5. J. K. WARKENTIN, Utilization Instructions for $Q A D M O D-G P$ - A PC Version of QADMOD-G with Geometric Progression Buildup Factors, RSIC Code Package CCC-565, November (1990).

6. MicroShield User's Manual, Ver. 6.21, Grove Software, Inc, Lynchburg, VA, March (2006).

7. H. FEUERSTEIN, S. HORN AND G. KIESER, TRITEX - A ferritic Steel Loop with Pb-15.8Li Facility and Operation, Forschungszentrun Karlsruhe Report, FZHA 6286, May (1999).

8. H. MORIYAMA, et al., "Tritium Recovery from Liquid Metals," Fusion Engineering and Design, 28, 1995, p. 226-239.

9. M. T. PORFIRI, ITER ORE: status of art and summary of the studies at 2007, ENEA Report, FUSTN-SA-SE-R-178, Rev. 2, May (2008).

6. J. K. WARKENTIN, Utilization Instructions for QADMOD-GP - A PC Verions Version of QADMOD-G with Geometric Progression Buildup Factors, RSIC Code Package CCC-565, November (1990).

7. MicroShield User's Manual, Ver. 6.21, Grove Software, Inc, Lynchburg, VA, March (2006).

8. H. FEUERSTEIN, S. HORN AND G. KIESER, TRITEX - A ferritic Steel Loop with Pb-15.8Li Facility and Operation, Forschungszentrun Karlsruhe Report, FZHA 6286, May (1999). 
9. H. MORIYAMA, et al., "Tritium Recovery from Liquid Metals," Fusion Engineering and Design, 28, 1995, p. 226-239.

10. A. NATALIZO, M. T. PORFIRI, Revison of the ORE assessment for the Port-Interfacing Systems, ENEA Report, FUS-TN-SA-SE-R-140, December (2005) M. T. PORFIRI, ITER ORE: status of art and summary of the studies at 2007, ENEA Report, FUS-TN-SASE-R-178, Rev. 2, May (2008).. 